Environment Conservation Journal 15(3) 109-113, 2014

ISSN 0972-3099 (Print) 2278-5124 (Online)

Abstracted and Indexed

\title{
Rearing performance of Philosamia ricini (Eri silkworm) in different seasons of Ujjain district
}

\author{
Shubhangi Vaidya $\bowtie$ and UlkaYadav
}

Received:12.08.2014

Revised: 14.10.2014

Accepted:28.10.2014

\begin{abstract}
India has the unique distinction of being only country producing all the five commercially traded varieties of natural silk namely Mulberry, Eri, Muga, Temperate tasar and Tropical tasar. The silk produced by Philosama ricini is called Eri silk. Eri silk is known as Non Violence silk or Piece silk. It is also said to be Poor Person's silk. The Eri silkworm (Philosamia ricini) is multivoltine, holometabolus, non-mulberry, completely domesticated and feed on castor (Ricinus communis) leaves. We observed the effect of different seasons on rearing performance of Eri silkworm in respect of different larval parameters (larval weight, larval length, ERR\% and pupation) and cocoon parameter (cocoon weight, pupae weight, shell weight \& shell \%). Our findings clearly indicated that the rearing performance of Eri silkworm was better in spring season than winter and autumn season of Ujjain district M.P.
\end{abstract}

Keywords: Castor leaves, cocoon parameters, Eri-silkworm (Philosamia ricini), larval parameters, season

\section{Introduction}

The reduction of rural poverty continues to be a paramount goal of the developing countries like India. So, for various strategies have been pursued to address this concern and the rural employment creation is one of the major aspects. Apart from the North-East region, Eri culture is also in practice in states of West Bengal, Bihar and Orissa (Krishna Rao, 2003) Recently, Ericulture is being introduced in Madhya Pradesh, Delhi, Punjab, Karnataka and Maharashtra (Kshama Giridhar et. al., 2007).India has the unique distinction of being only country producing all the five commercially traded varieties of natural silks namely Mulberry, Eri, Muga, Tropical tasar and temperate tasar. India has a distinct advantage of practicing sericulture all through the year, yielding a stream of about 4-6 crops as a result of its tropical climate. Silk obtained from sources other than mulberry are termed as Non-Mulberry. Compared with the other non mulberry silkworm, Eri silkworm hasa very rich harvest. Apart from the benefits of indoor rearing, silkworm itself is extremely hardy and less susceptible to disease. With feeding on the castor leaves, it is possible to obtain a $75-85 \%$ effective yield.The present global scenario clearly indicat

Author's Address

${ }^{1}$ Department of Zoology, Microbiology and Bioinformatics Govt. P.G.M.V.M. Ujjain M.P

E-mail:svaidya1961@hotmail.com -es the enormous opportunities for the Indian silk Industry, because the India is the second largest producer of silk in world with annual silk production 18,475 Tones (2007-08), (Indian Silk, 2008). In India Sericulture is essentially villagebased industry providing employment to a sizable activity falling under the cottage and small-scale sector. It particularly suits rural-based farmers, entrepreneurs and artisans, as it requires low investment but, with potential for relative higher return. It provides income and employment to the rural poor specially farmers with small land holding and marginalized weaker section of the society. Several socio-economic studies have affirmed that the benefit-cost ratio in sericulture is highest among comparable agricultural crops. Sericulture involves rearing of silkworm and production of silk. Silk is highly valued natural textile fiber of animal origin. No other fabric has fascinated man so continuously over millennia as silk. Silk is so popular because of their qualities like texture, lustre, tensile qualities, comfort adaptability to all climatic condition, royal look, Natural Shine, Soft, Inherent affinities for dies and vibrant colors, high absorbance and light weight. G. Ganga and Sulochana Chetty (1995), Anonymous (1984, 1994). The Castor (food plant of Eri silkworm) can be grown on Semi-arable and degraded soil. It is also grown on wasteland and in 
rain-fed condition. Castor plant does not attract either cattle or wild animals. This makes cultivation of castor more suitable for tribal areas, adjacent to the forest. Castor plants and Eri silkworm are also considered to be hardier. Eri silkworm itself is nutritious. It does not make annoying sound or odors. It also does not need water to drink and has less mortality rate then other silkworm. The Cocoon of Eri silkworm cannot be reeled but are being spun into thread like cotton and the weaving done in hand loom under cottage industry. In India National organization established in 1949 as a statutory body under the Ministry of Textile, Government of India, for the overall development of sericulture and silk industry. Its headquarters is located in Bangalore. Erisilk is known as Poor Person's silk (as it is not so enormously priced as other silk types and its cost of production is very less than other silk) Sarkar D.C. (1988) It is also known as Non violence Silk (There is no need to kill the pupae inside the cocoon as in case of other silk because Eri silk is spun into thread like cotton) and cocoon of Eri silkworm is open mouthed at one end. Texture of the Eri fabric is coarse, fine and dense. It is very strong and durable and has elasticity, darker heavier than other silk. It blends well with wool and cotton. The Thermal property (Warm in winter and Cool in summers) of Eri silk makes it a suitable fabric for shawls, Jackets, and Blankets. Baby dresses are also made from Eri silk because of its soft texture and moisture absorbent qualities.

\section{Material and Methods}

The present study was conducted in the Zoology Department of Govt. P.G.M.V.M. Ujjain M.P. The rearing performance was conducted during September-October 2010 (Autumn Season), November-December 2010 (Winter Season) and January -February 2011 (Spring Season). During experiment temperature and humidity were recorded. Eggs of Eri silkworm (Philosamia ricini) were collected from Govt. Sericulture Center Indore M.P, and standard rearing method was used suggested by (Choudhary, 1982). Larval duration were counted in days, larval weight and larval length were calculated and recorded of $\mathrm{V}^{\text {th }}$ instar mature larvae in gram and $\mathrm{cm}$ respectively. While ERR (effective rate of rearing) and pupation were calculated by the following formulas in percentage (\%)

$$
E R R=\frac{\text { Total no. of cocoon formed }}{\text { Total no. of worms brushed }} X 100
$$

$$
\text { Pupation }=\frac{\text { Total no. of pupae formed }}{\text { Total no. of worms brushed }} X 100
$$

Cocoon weight, pupae weight, shell weight were calculated in gram while shell ratio (in percentage) was calculated by the following formula:

$$
\text { Shell ratio }=\frac{\text { Shell weight }}{\text { Cocoon weight }} \times 100
$$

\section{Results and Discussion}

The data reveals that larval duration (days), larval weight $(\mathrm{gm})$, larval length $(\mathrm{cm})$, ERR\%, pupation $\%$ (larval parameter) in Table No.-1 and cocoon weight $(\mathrm{gm})$, pupae weight $(\mathrm{gm})$, shell weight $(\mathrm{gm})$ shell \% (Cocoon parameter) in Table No.2 were recorded in different seasons of Ujjain District. The biotic factors- maximum and minimum temperature and relative humidity were also recorded for rearing period in Table No.3.The data reveals that larval duration (days) in different seasons were recorded minimum in spring (19 days) followed by autumn (20 days) and winter (26 days) The larval weight (gm) was recorded maximum 7.5 gm in spring followed by $7.5 \mathrm{gm}$ in winter and $7.30 \mathrm{gm}$ in autumn. Similarly, larval length $(\mathrm{cm})$ recorded maximum $7.5 \mathrm{~cm}$ in spring followed by $6.20 \mathrm{~cm}$ in autumn and $5.5 \mathrm{~cm}$ in winter. We observed ERR \% of spring was maximum $90 \%$ followed by $85 \%$ both in autumn and winter. The pupation percentage was recorded maximum in spring $90 \%$ followed $89 \%$ during winter $88 \%$ during autumn season.The data revealed to cocoon parameters were also recorded in different seasons of Ujjain District during 2010-11. The cocoon weight (gm) was recorded maximum in spring $3.56 \mathrm{gm}$ followed by $3.55 \mathrm{gm}$ in winter and $3.49 \mathrm{gm}$ in autumn. The pupae weight $(\mathrm{gm})$ recorded maximum in spring 3.15 $\mathrm{gm}$ and $3.10 \mathrm{gm}$ in autumn and winter season. The shell weight (gm) was recorded maximum in $0.52 \mathrm{gm}$ in spring and $0.50 \mathrm{gm}$ in both autumn and winter season. The shell ratio in \% was calculated and found maximum $15.19 \%$ in spring season and $14.50 \%$ winter in season and $14.68 \%$ in autumn season. 
Table 1: Shows rearing performance of Eri silkworm (Philosamia ricini) in autumn, winter, spring Seasons of Ujjain (M.P.) in respect of larval parameter

\begin{tabular}{|l|l|l|l|}
\hline $\begin{array}{l}\text { Larval } \\
\text { Parameter }\end{array}$ & $\begin{array}{l}\text { Autum } \\
\text { n }\end{array}$ & Winter & Spring \\
\hline Larval Duration & 20 days & 26 days & 19 days \\
\hline Larval weight & $7.30 \mathrm{gm}$ & $7.50 \mathrm{gm}$ & $7.50 \mathrm{gm}$ \\
\hline Larval length & $6.20 \mathrm{~cm}$ & $5.50 \mathrm{~cm}$ & $7.50 \mathrm{~cm}$ \\
\hline ERR & $85 \%$ & $85 \%$ & $90 \%$ \\
\hline Pupation & $88 \%$ & $89 \%$ & $91 \%$ \\
\hline
\end{tabular}

Table 2: Shows- rearing performance of Eri silkworm (Philosamia ricini) in autumn, winter, spring seasons of Ujjain (M.P.) in respect of cocoon parameter

\begin{tabular}{|l|l|l|l|}
\hline $\begin{array}{l}\text { Cocoon } \\
\text { Parameter }\end{array}$ & Autumn & Winter & Spring \\
\hline Cocoon Weight & $3.49 \mathrm{gm}$ & $3.55 \mathrm{gm}$ & $3.56 \mathrm{gm}$ \\
\hline Pupae weight & $3.10 \mathrm{gm}$ & $3.10 \mathrm{gm}$ & $3.15 \mathrm{gm}$ \\
\hline Shell Weight & $0.50 \mathrm{gm}$ & $0.50 \mathrm{gm}$ & $0.52 \mathrm{gm}$ \\
\hline Shell\% & 14.68 & 14.50 & 15.19 \\
\hline
\end{tabular}

Table 3: Shows- temperature and humidity in autumn, winter, spring seasons of Ujjain (M.P.) during rearing performance of Eri silkworm

\begin{tabular}{|c|c|c|}
\hline Seasons & Temperature $\left({ }^{\mathbf{O}} \mathbf{C}\right)$ & Humidity(\%) \\
\hline Autumn & $27 \pm 4$ & $75 \pm 3 \%$ \\
\hline Winter & $20 \pm 3$ & $70 \pm 3 \%$ \\
\hline Spring & $22 \pm 3$ & $78 \pm 3 \%$ \\
\hline
\end{tabular}

On the basis of result obtained we can say that our findings as in resembles to the finding of other scientists of different part of the country. The potentially of Eri culture as a viable subsidiary has been highlighted by many workers. Jayaprakash et.al. (2003,2005), Saratchandra (2003), Prakash et.al. (2003) and Rama Rao et .al, (2005). Larval and cocoon performance of silkworms have been effected by seasons and food plants. Ghosh B. et.al.(1993) studied analysis of quantitative tracks of multivoltine silkworm Bombyxmori L (Lepidoptera; bombycidae) in varied environments. Gupta, B. K., et.al. (1992) worked on egg yielding capacity of different races of silkworm Bombyxmori L.There is extensive information available on effect of seasons, micronutrients and different food plant on rearing performance of
Erisilkworm. Theeffect of host plant on the growth and development in Erisilkworm Philosamia ricini has reported by Biswas N. and P.K.Das (2001), Hajarika et.al. (2000, 2003), Rajesh Kumar et.al. (2010), PritiPragyan Ray (2010) studied on the effects of food plant and seasons on the larval development and cocoon characters of Eri worm.Jaiswal K. et.al. (2006) studied comparative study on rearing performance of different ecorace of erisilkworm Philosamia ricini in monsoon season of Uttar Pradesh. Rajesh et.al.worked on Philosamiaricini in spring ,rainy and winter.Jaiswalet.al.(2008), Rajesh Kumar (2010),worked on rearing performance of Eri silkworm Philosamiaricini in monsoon season of Uttar Pradesh. Selvakumaret.al. (2008) studied a new device to maintain rearing temperature and humidity.Gohain and R.Borua (1983) studied effect of temperature and humidity on development survival and ovipositor in laboratory population of Eriworm, PhilosamiariciniL.. Joshi K.L. (1985) Khawaja (1989), Basavarajappa S.,et. al., (1996),Mubashir Hussain (2011), Pandey Priyankaet.al. (2006,2008) ,Gangwar S.K. (2011) studied effect of seasonal variation on the Survival percentage and cocoon yield in some breeds of the silkworm, Bombyxmori LThe seasons of different regions influences the larval growth, larval duration, ERR\%, pupation\% and cocoon weight, pupal weight, shell weight and shell ratio\%. The effect of seasons on the growth and development in the insects has been reported (Reddy et.al. 1989, Muthukrishnan and Pandian 1987).Production of silk depends on production of seed cocoons. Department of sericulture has popularized Eri culture in the states industries, production of commercial seed within the organized seed forms, implementation of new rearing technology. Reddy D.N.R. et al,(1989), Singh, B.K.et.al.(2006). From our result it is obviously concluded that the performance of Erisilkworm is the best in spring season followed by autumn and winter season in Ujjain district in respect of different larval as well as cocoon parameters.

\section{References}

Anonymous 1984. A few guidelines to Eri Silkworm Rearing. Regional Sericultural Research Station, Central silk Board Titabarl, Assam, pp. 6 
Anonymous 1994. Package of practices for higher yields.Univ.Agric.Sci.and State Dept.agric, Bangalore, p.98.

Choudhary S.N. 1982. Eri silk industry, Published by Directorate of Sericulture and weaving Government of Assam.pp.16-25.

Biswas N. and P.K. Das.2001. Effect of food plants species on rearing performance of Eri silkworm (Philosamia ricini DONOVAN ). Bull. Ind. Acad . Seri. 5

Basavarajappa, S. Haque,Band Savanurmath,C.J.1996 Effect of seasonal variation on the survival percentage and cocoon yield in some breeds of the silkworm Bombyx mori $L$. $J$. Asiatic Bangladesh, Sci.22(2);131-136.

Ganga G. and SulochanaChetty 1995 - An introduction to sericulture handbook.

Gangwar S.K.2011.Screening of region and season specific Bivoltine silkworm (bombyxmori Linn.) hybrid breeds of West Bengal in spring and summer season of Uttar Pradesh climatic condition.International Journal of Plant, Animal and Environmental Sciences, Volume :1

Ghosh,B.,Chattopadhyay,S.Rao,P.R.,T.Das, S.K.Roy, G.C.Sen S.K.and Sinha S.S. 1993. Analysis of quantitative tracks of multivoltinesilkworm, Bombyx mori L.(Lepidoptera; bombycidae) in varied environments Uttar Pradesh. $J$. Zool.; 13(1); 47-51.

GohainR.andR.Borua 1983.Effect of temperature and humidity on development survival and oviposition in laboratory populations of Eriworm,(Boisduval) (Lepidoptera saturniidae) Archives of Physiology and Biochemistry, Volume 91 issue 2 July 1983,pages 87-93.

Gupta,B.K.Sinha,A.K. and Das B.C.1992 Studies on egg yielding capacity of different races of silkworm, Bombyx moriL.Gobios; 18(4)173-176

Hajarika U .,Barah A. ,Phukan J.D., and Benchamin K.V. 2003 Studies on the effect of different food plants and seasons on the larval development and cocoon characters of Eri silkworm Samia Cynthia ricini Boisduval.Bull.,Ind.Acad.Seri.7(1)

Hajarika U., Benchamin K.V.,Barah A. and Phukon J.C.D.,2000. Studies on the effect of different food plants and seasons on the larval development Eri silkworm Samia Cynthia riciniBoisduval.Abst.of seminar on Sericulture research and development in muga and eri.8-9 November .p.8.

Jaiswal, K., Gangwar, S.K. and Rajesh Kumar 2006.Comparative study on rearing performance of different eco-race of eri silkworm (Philosamia ricini) in monsoon season of Uttar Pradesh. In: Proceeding of National seminar on prospects and problem of sericulture as an economic enterprise in North- West India.2006 ,Dehradun, India, 483-485

JaiswalK..et al.,2008 Rearing performance of ErisilkwormPhilosamia ricini in monsoon season of Lucknow .National Journal of life science ,5(2)pp.251253.

JayaPrakash,P.,B.V.S.Rao,K.VenkateshwarRao,J.V.KrishnaRa o and B.R.R.P.Sinha 2003 Reintroduction of eri culture in Andhra Pradesh; Hopes galore. Indian Silk,19-20.

Jayaprakash,P.A.Sasikala and N.Suryanarayana 2005 Ericulture- A tool for rural women development in Andhra Pradesh,India.Conference Papers (3.18) In:The $20^{\text {th }}$ Congress of the International Sericultural Commission, Bangalore, 106-109

Joshi,K. L.,1985.Studies on growth index for Eri Silkworm Philosamia ricini Hutt. (Lepidoptera;saturniidae). Sericologia, 25 (3);313-319.

Khawaja, 1989, Comparative studies on the prospect of rearing silkworm Bombyx mori L.,during the autumn and spring season at Faisalabad. M,sc..(Hons.) Thesis.Entomol.,Univ.Agric F aisalabad, Pakistan.

Krishna Rao,J. V 2003. Large scale development of Ericulture in India. Indian Silk, 42(1) ; 27-29.

KrishnaswamiS.M,N. Narsimhanan and S.K,Suryanarayana 1973 Sericulture Manual 2 Silkworm Rearing.FAOAgric.Serv. Bull. Rome.15 1-131.

KshamaGiridhar, Mathanta, J.C. and Deole, A.L. 2007 Raw silk production.Indian Silk, 46 (6): 43-44.

Mubashar Hussain, Shakil Ahmad Khan, Muhammad Naeem and Ata-Ul-Mohsin 2011. Effect of relative humidity on factors of seed cocoon production in some inbred silk worm (Bombyx mori) Lines.International Journal of Agriculture and Biology., Vol.13.No.1, 57-60

Muthukrishnan and T.J.Pandian 1987.Relationship between feeding and egg population in some insects. Proc., Indian Acad. Sci (Anim .Sci).96; 171-179.

Pandey Priyanka, Tripathi S.P., Shrivastav V.M.S. 2006. effect of ecological factors on larval duration of Bombyxmorilinn. Journal of ecophysiology\&Occupation Health Vol.6 Issue $3 \& 4$

Pandey Priyanka and S.P..Tripathi, 2008. Effect of humidity in the survival and weight of Bombyx mori L. larvae Malays. Appl. Biol. 37:37-39.

Prakash K.S. ,R.N. Prasad; C.V.N.Ravikishore; M.RamaRao;J.V.KrishanaRao and R.P.Khanna 2003 Eri 
culture-An additional source of income for tapioca farmers .Indian Silk, 41 (12)29-30

Priti Pragyan Ray, T. V. Rao and Purushattam Dash 2010 Performance of promising ecoraces of eri (Philosamia ricini) in agroclimatic conditions of western Odisha The bioscon 5 (2): 201-205

Rajesh kumar and S. K. Gangwar 2010 Impact of varietal feeding on samiaricinidonovain spring and autumn season of Uttarpradesh Journal of agricultural and biological science vol. 5 , no. 3 ,

Rajesh Kumar and VadamalaiElangovan 2010 Rearing Performance of Eri Silkworm Philosamia ricini in monsoon Season of Uttar Pradesh Asian J. Exp. Biol. Sci., Vol 1(2) : $303-310$

Rama Rao, M., R. N. Prasad, and N.Suryanarayana 2005 Ericulture-An additional income for tapioca (cassava)grower and a good nourishment to the malnutritioned tribal populace.Conference Papers (3.16 )In; The $20^{\text {th }}$ Congress of the International Sericulture Commission, Bangalore 94-98
Reddy, D.N.R., Kotikal, Y.K. and Vijayendra, M., 1998, Development and silk Yield of Eri silkworm Samiacynthi aricini (Lepidoptera; Saturnidae) as influenced by the food plants. Mysore J. Agric. Sci., 23: 506-508

Sarkar, D.C. 1988 Ericulture in India .Central silk board, Publ. Bangalore, India P .28.

Saratchandra, B.2003 A thought for development of eri culture in India. Indian silk vol $41: 25-28$.

Selvakumar, T., Leela Devi, Mallikarjuna 2008 A new device to maintain rearing temperature and humidity. Indian silk, vol.47: 611-14

Singh,B.K. and ,Das,P.K 2006. Prospects and problems for development of Eri culture in Non-traditional states In; Proceeding of Regional seminar on Prospects \& problem of sericulture as an economic enterprise in North West India 2006,Dehradun ,312-315. 